lasers made by deep proton bombardment, and that a potentially useful lightwave pulse regenerator can be made by taking advantage of their unusual behavior.

\section{ACKNOWLEDGMENT}

We would like to thank A. E. Bakanowski, H. E. Elder, and A. J. Schorr for supplying the devices used.

\section{REFERENCES}

[1] J. A. Copeland, "Semiconductor-laser self pulsing due to deep level traps," Electron. Lett., vol. 14, pp. 809-810, Dec. 7, 1978.
[2] - "Triggerable semiconductor lasers and light-coupled logic," to be published.

[3] T. L. Paoli found that 25 of a group of 110 proton-bombarded devices simular to ours showed a discontinuous jump in light output in the vicinity of threshold. See "Saturable absorption effects in the self-pulsing (AlGa)As junction laser," Appl. Phys. Lett., vol. 34, pp. 652-655, May 15, 1979.

[4] T. P. Lee and R. Roldan, "Subnanosecond light pulses from GaAs injection lasers," IEEE J. Quantum Electron., vol. QE, pp. 551552, Nov. 1969.

[5] R. W. Dixon and W. B. Joyce, "A possible model for sustained oscillations (pulsations) in (Al,Ga)As double-heterostructure lasers," IEEE J. Quantum Electron., vol. QE-15, pp. 470-474, June 1979.

[6] C. H. Henry, private communication.

\title{
Low Threshold Be Implanted (GaAl)As Laser On Semi-Insulating Substrate
}

\author{
D. WILT, N. BAR-CHAIM, S. MARGALIT, I. URY, M. YUST, AND A. YARIV
}

\begin{abstract}
Be implanted stripe geometry double heterostructure lasers have been fabricated on a semi-insulating GaAs substrate, with threshold currents as low as $15 \mathrm{~mA}$ for a cavity length of $100 \mu \mathrm{m}$. The laser has been monolithically integrated with a metal-semiconductor field-effect transistor.
\end{abstract}

$\mathrm{T}$ HE integration of semiconductor based optical and electronic devices has gained much interest recently. The most important step in such devices is the fabrication of lowthreshold injection lasers on semi-insulating (SI) substrates, such as GaAs. Lasers, which have been fabricated on SI GaAs substrates, include the crowding effect laser [1], the $T$-laser [2], and the transverse-junction-stripe (TJS) laser [3]. The latter has been successfully operated continuously at temperatures above $100^{\circ} \mathrm{C}[4]$.

We have recently demonstrated monolithic integration of GaAs lasers with several electronic devices. These include a Gunn oscillator [5] and metal-semiconductor field-effect transistor [2]. Recently, an integrated optical repeater [6] consisting of a detector, an electronic amplifier, and a laser was developed.

In all these experiments, the laser used was of the crowding effect type which, although lending itself readily to integration, possesses relatively high $(>100 \mathrm{~mA})$ currents. In this paper, we report on the fabrication of a low-threshold new type of double-heterostructure (GaAl)As laser on an $\mathrm{Si} \mathrm{GaAs}$ substrate using $\mathrm{Be}$ ion implantation. This laser is a lateral

Manuscript received December 13, 1979. This work was supported in part by the Office of Naval Research and the National Science Foundation.

The authors are with California Institute of Technology, Pasadena, CA 91125 .

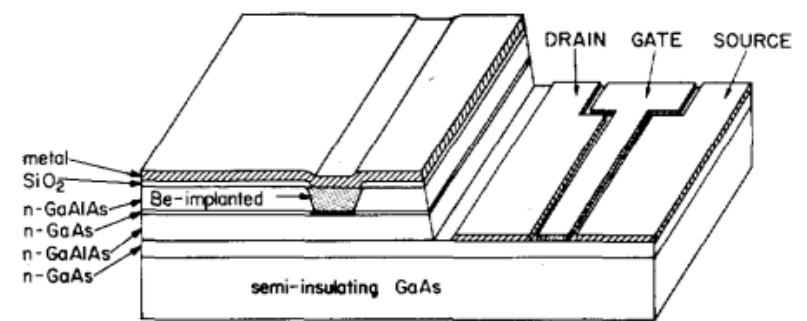

Fig. 1. The Be implanted laser with the integrated MESFET on semiinsulating $\mathrm{GaAs}$.

version of the Be implanted laser on a conductive substrate [7]. The laser has been monolithically integrated with a MESFET, giving rise to a direct modulation of the laser light.

The structure of the device is shown in Fig. 1. Fabrication of the device starts with the growth of four n-type layers on $\mathrm{Cr}$ doped GaAs substrate by liquid phase epitaxy. The bottom GaAs layer is doped to $\sim 10^{16} \mathrm{~cm}^{-3}$ and its thickness is $0.8 \mu \mathrm{m}$. The other three layers form a typical double heterostructure with thicknesses of $3 \mu \mathrm{m}$ for the lower $\mathrm{Ga}_{0.6} \mathrm{Al}_{0.4} \mathrm{As}, 0.25 \mu \mathrm{m}$ for the GaAs active layer, and $1 \mu \mathrm{m}$ for the upper $\mathrm{Ga}_{0.6} \mathrm{Al}_{0.4} \mathrm{As}$. The wafer is covered with $2500 \AA$ of $\mathrm{SiO}_{2}$ and a layer of photoresist in which stripes with width of $4 \mu \mathrm{m}$ are opened. A 100$\mathrm{keV} \mathrm{Be}$ implantation is then performed at room temperature with a dose of $3 \times 10^{15} \mathrm{~cm}^{-2}$, followed by a 40 min anneal at $800^{\circ} \mathrm{C}$. This results in diffusion of the implanted stripe down to the $\mathrm{GaAs}$ active region. The Be region has a minimal lateral diffusion under the $\mathrm{SiO}_{2}$ layer and in most cases the p-n junction is located within the GaAs active region. This follows from the different diffusion coefficients of $\mathrm{Be}$ in $\mathrm{GaAs}$ and GaAlAs [7]. After a shallow $\mathrm{Zn}$ diffusion into the stripe side, an evaporation of $\mathrm{Au}-\mathrm{Zn}$ is performed and alloyed for the $\mathrm{p}$ - 


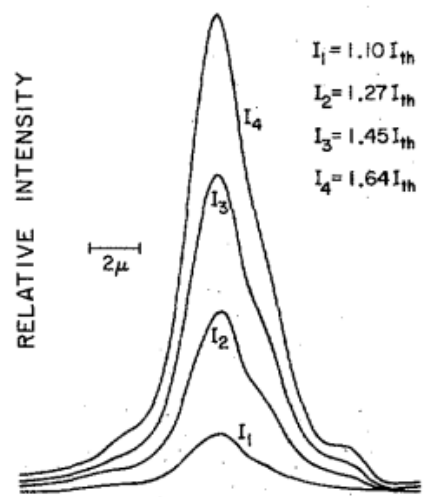

DISTANCE

Fig. 2. The near field pattern of the Be implanted laser.

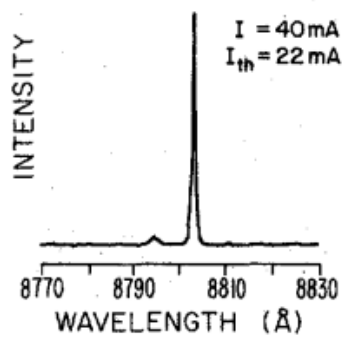

Fig. 3. Emission spectrum of the Be implanted laser.

contact. Then a mesa is formed by etching down to the nGaAs layer with $1: 8: 8,\left(\mathrm{H}_{2} \mathrm{SO}_{4}: \mathrm{H}_{2} \mathrm{O}_{2}: \mathrm{H}_{2} \mathrm{O}\right)$, followed by a shadow evaporation of $\mathrm{Au}-\mathrm{Ge}$ and Au. The Schottky gate is formed using a self-aligned process and a lift-off technique. After alloying the Au-Ge contacts, the substrate is thinned and the wafer is cleaved into individual devices.

Typical pulsed threshold currents for lasers with a $4-\mu \mathrm{m}$ stripe width and cavity lengths of 250 and $125 \mu \mathrm{m}$ were 35 and 20 $\mathrm{mA}$, respectively. The lowest pulsed threshold current found was $15 \mathrm{~mA}$ for a cavity length of $100 \mu \mathrm{m}$. The stable nearfield pattern of the laser is shown in Fig. 2. The light versus current characteristics were linear and kink free up to $10 \mathrm{~mW}$ output power. The measured differential quantum efficiency was 50 percent, approximately. The spectrum of the laser is shown in Fig. 3. It shows essentially single-mode operation.

In the stripe geometry used, the p-n junction is formed in a closed, current confined structure, which prevents current spreading around the stripe. This limits the gain region to the stripe width and to minority carrier diffusion tails on either side of the stripe, thus giving rise to an effective confinement of

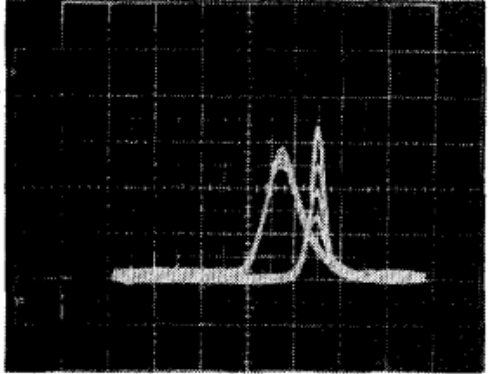

Fig. 4. Laser current (left scale $10 \mathrm{~mA} /$ div) and light output (right scale, arbitrary units) for several gate voltages $(0.5 \mathrm{~V} / \mathrm{step})$. Horizontal scale is $20 \mathrm{~ns} / \mathrm{div}$.

the lasing filament at all current levels. The gate length was $8 \mu \mathrm{m}$ and transconductance ranged from 5 to $10 \mathrm{mmho}$. The effect of the gate voltage on the light output is shown in Fig. 4. The left and right curves correspond to the current through the laser and light output, respectively. When the laser and the MESFET are operated in series with voltage applied between the laser anode and the FET source, the laser light output is varied by applying a negative voltage to the gate.

In conclusion, we have fabricated ( $\mathrm{GaAl}) \mathrm{As}$ double-heterostructure lasers on semi-insulating substrates using Be ion implantation. The $\mathrm{CW}$ operation of these lasers and the ease of integration with electronic devices make these attractive devices for optoelectronic systems. This was demonstrated by integration of the laser with a metal-semiconductor fieldeffect transistor.

\section{REFERENCES}

[1] C. P. Lee, S. Margalit, and A. Yariv, "Double-heterostructure GaAsGaAlAs injection lasers on semi-insulating substrates using carrier crowding," Appl. Phys. Lett., vol. 31, pp. 281-282, 1977.

[2] I. Ury, S. Margalit, M. Yust, and A. Yariv, "Monolithic integration of an injection laser and a metal semiconductor field effect transistor," Appl. Phys. Lett., vol. 34, pp. 430-431, 1979.

[3] C. P. Lee, S. Margalit, I. Ury, and A. Yariv, "GaAs-GaAlAs injection lasers on semi-insulating substrates using laterally diffused junction," Appl. Phys. Lett., vol. 32, pp. 410-412, 1978.

[4] H. Kumabe, T. Tanaka, H. Namizaki, M. Ishii, and W. Susaki, "High temperature single-mode $\mathrm{cw}$ operation with a junction up TJS laser," Appl. Phys. Lett., vol. 33, pp. 38-39, 1978.

[5] C. P. Lee, S. Margalit, I. Ury, and A. Yariv, "Integration of an injection laser with a Gunn oscillator on a semi-insulating $\mathrm{GaAs}$ substrate," Appl. Phys. Lett., vol. 32, pp. 806-807, 1978.

[6] M. Yust, N. Bar-Chaim, S. H. Izadpanah, S. Margalit, I. Ury, D. Wilt, and A. Yariv, "A monlithically integrated optical repeater," $A p p l$. Phys. Lett., vol. 35, pp. 795-797, 1979.

[7] N. Bar-Chaim, M. Lanir, S. Margalit, I. Ury, D. Wilt, M. Yust, and A. Yariv, "Be implanted (GaAl)As stripe geometry lasers," Appl. Phys. Lett., to be published. 